\title{
Werner Bahner
}

Formen, Ideen, Prozesse $\cdot$ Band 2 


\title{
Literatur und Gesellschaft
}

\author{
Herausgegeben von der \\ Akademie der Wissenschaften der DDR \\ Zentralinstitut für Literaturgeschichte
}




\title{
Werner Bahner
}

\section{Formen, Ideen, Prozesse in den Literaturen der romanischen Völker}

\author{
Band 2: \\ Positionen und Themen der Aufklärung
}

Akademie-Verlag $\cdot$ Berlin 
Erschienen im Akademie-Verlag, 108 Berlin, Leipziger Str. 3-4

(C) Akademie-Verlag Berlin 1977

Lizenznummer : $202 \cdot 100 / 232 / 77$

Gesamtherstellung: IV/2/14 VEB Druckerei "Gottfried Wilhelm Leibniz", 445 Gräfenhainichen $\cdot 4855$

Bestellnummer: $7532055(2150 / 52) \cdot$ LSV 8051

Printed in GDR

DDR $9,50 \mathrm{M}$ 